$$
\text { O2 }-1749
$$

\title{
SIMPLEX, A CODE FOR THE SOLUTION OF LINEAR PROGRAMMING PROBLEMS
}

Hoyt Walker

Laureace S. Hall

June 1975

Prepared for U.S. Energy Research \& Development Administration under contract No. W-7405-E.7g-48

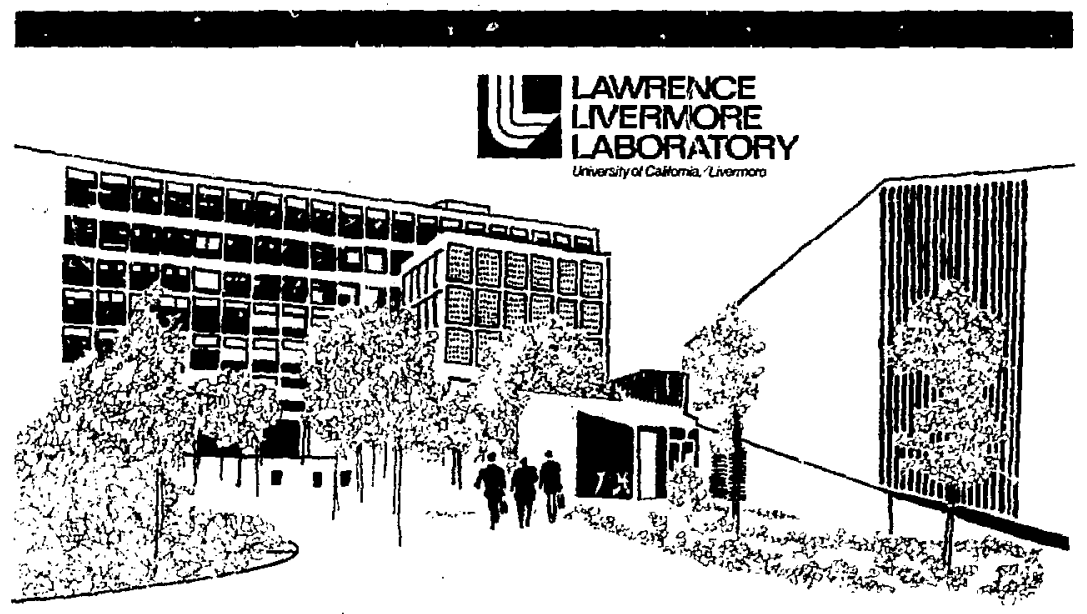

MWh 


\section{NOTICE}

"Thls report was prepared as an account of work syonsored by the Ur!ted States Government. Neither the United States ic: the United Stales Eneray Research \& Development Administration, nor any of their employees; nor any of their contractrrs. subcontractors, or their employces, makes any warcanty, express or implied, or assumes any legal wartanty, express or implied, or assumes any lesal completentis or usefulness of any information, apparatus, producd or process disclosed or represents that its use would not infringe represents that its ux
privately-owned rights."

Printed in the United States of America Available from

National Technical Information Service U.S. Department of Commerce 5285 Port Royal Road

Springfield, Virginia 22151

Price: Printed Copy $\$$ *; Microfiche $\$ 2.25$

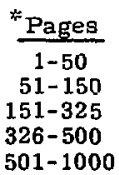

NTIS Selling Price 
Distribution Category UC-20

\section{迧 \\ LAWRENCE LNERMORE LABORATOFY

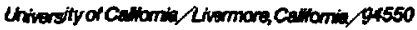

\section{UCRL -51820 \\ SIMPLEX, A CODE FOR THE SOLUTION OF LINEAR PROGRAMMING PROBLEMS}

Hoy $t$ Walker

Lauronce S. Hall

MS. date: June 1975

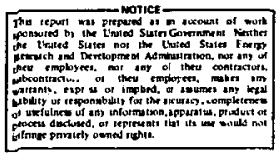




\section{Contents}

Abstract . . . . . . . . . . . . . . . . . . . . . 1

Section 1. The Linear Progranming Problem . . . . . . . . . . 1

Section 2. The Simplex Procedures . . . . . . . . . . . . 4

Section 3. User-Level Instructions for SIMPLEX . . . . . . . . 7

Section 4. Examples . . . . . . . . . . . . . . . . 16

References . . . . . . . . . . . . . . . . . . . 20

Appendix A - Code Lis:Ing of SIMPLEX (Including routines used for the ieutral injection problem) . . . . . . . . 21

Appendix B - The Sequence of Iterations Showing the Convergenra of the Simplex Algorithm for $n=40$ in the Neutral Injection Problem. (The solid curve is the analytic result. The vertical scale is arbitrary and is set by the computer. Relative values may be determined by the height of the analytic curve.) . . 43 


\section{SIMPLEX, A CODE FOR THE SOLUTION OF LINEAR PROGRAMMING PROBLEMS}

\section{Abstract}

A set of procedures is described for solution of a general linear programing problem that seeks to maximize the linear functional

$W=\sum_{j=1}^{i} c_{j} x_{j}$ for coordinates $x_{j} \geq 0$, subject to m restrictions of the form $\sum_{j=1} a_{i j} x_{j} \leq b_{i}$ and $\ell$ restrictions of the form $\sum_{j=j} a_{i j} x_{j}=b_{1}$. An IRLTRAN computer code, which performs the maximization, has been developed to follow these procedures and is also descrlbed. Illustration of the use of the simplex procedure is given.

\section{The Linear Programming Problem}

A general linear programming problem is one that seeks to maximize the linear functional

$$
W=\sum_{j=1}^{n} c_{j} x_{j}
$$

for coordinutes $\mathrm{x}_{j} \geq 0$ subject to the set of m inequality constraints

$$
\sum_{j=1}^{n} a_{1 j} x_{j} \leq b_{i}, \quad i=1,2, \ldots, m
$$

and $\ell$ equality constraints

$$
\sum_{j=1}^{n} a_{i j} x_{j}=b_{1}, \quad 1=m+1, m+2, \ldots, m+\ell .
$$


Because the set of points satisfying the constraints is convex (that is, because, in the $\mathbf{n - d i m e n s i o n a l ~ h y p e r s p a c e}$ of the vector $\left\{x_{. j}\right\}$, every point that lies on a straight line between any two points satisfying the constraints itself satisfles the constraints), the extrema of $W$ will be obtained $a i$ one of the extreme points (vertices) of the constraint set. ${ }^{1}$ If we introduce the set of slack variables

$$
u_{i}=b_{1}-\sum_{j=1}^{n} a_{i j} x_{j},
$$

then the constraints take the form $x_{j} \geq 0, u_{i} \geq 0\left[u_{1}=0\right.$, for $(m+1) \leq 1 \leq$ $(m+l)]$, and a vertex corresponds to a point at which $n$ of the vartables $\left\{u_{i}, x_{j}\right\}$ vanish.

If $\left\{\xi_{j}\right\}, 1 \leq j \leq n$, is a subset of the variables $\left\{u_{1}, x_{j}\right\}$, all of which vanish when $W$ is maximal, then clearly we may use Eq. (4) to rewrite $W$, Eq. (1), obtaining

$$
W=\sum_{j=1}^{n} Y_{j} \xi_{j}+\delta,
$$

where $\mathrm{w}_{\max }=\delta$ and $\gamma_{j} \leq 0,1 \leq j \leq n$. Likewise $\left\{n_{i}\right\}, 1 \leq 1 \leq n+\ell$, the balance of the set of $n+m+\ell$ variables $\left\{u_{i}, x_{j}\right\}$, is given in terms of the $\xi_{j}$ by equations of the form

$$
-n_{1}=\sum_{j=1}^{i l} a_{i j} \xi_{j}+\beta_{1} .
$$

where $B_{1} \leq 0,1 \leq 1 \leq m+\ell$. The transformation of Eqs. (1) and (4) into Eqs. (5) and (6) vith non-postefve $\beta_{1}$ and $\gamma_{j}$ is accomplished by the simplex algorfthm. We summarize the procedures of the simplex algorithm in a convenient form by a discussion close to that of $G$. Owen. 1 
Equations (5) and (6) corrispond in self-explanatory fashion to the simplex tableau:

\begin{tabular}{|c|c|c|c|c|c|c|c|c|}
\hline & $E_{1}$ & $\xi_{2}$ & $\cdots$ & $\xi_{n-\ell}$ & $\xi_{n-\ell+1}$ & $\cdots$ & $\xi_{n}$ & 1 \\
\hline$-r_{1}$ & $a_{11}$ & $\alpha_{12}$ & $\cdots$ & $a_{1, n-l}$ & $a_{1, n-2,+1}$ & $\cdots$ & $\alpha_{1, n}$ & $B_{1}$ \\
\hline$-n_{2}$ & $\alpha_{21}$ & $\alpha_{22}$ & $\cdots$ & ${ }^{0}, n-1$ & $x_{2}, n-i+1$ & $\ldots$ & ${ }^{2}, n$ & $B_{2}$ \\
\hline$\vdots$ & $\vdots$ & $\vdots$ & $\because$ & $:$ & $\vdots$ & $\because$ & $\vdots$ & $\vdots$ \\
\hline$-n_{\text {ग }}$ & $\alpha_{\mathrm{m}, 1}$ & $\alpha_{\mathrm{m}, 2}$ & $\cdots$ & $a_{m, n-l}$ & $\alpha_{m, n-i+1}$ & $\cdots$ & $\alpha_{\mathrm{m}, \mathrm{n}}$ & $B_{m}$ \\
\hline$-n_{m+1}$ & $a_{m+1,1}$ & $a_{m+1,2}$ & $\cdots$ & $a_{m+1, n-2}$ & $a_{m+1, n-2-1}$ & $\cdots$ & $a_{m+1, n}$ & $B_{m+1}$ \\
\hline$\vdots$ & : & $\vdots$ & $\ddots$ & : & $\vdots$ & $\bullet$ & $\vdots$ & : \\
\hline$-\eta_{m+l}$ & $\alpha_{m+l, 1}$ & $\alpha_{m+\ell, 2}$ & $\cdots$ & $\alpha_{m+i, n-i}$ & $a_{m+2, n-2+1}$ & $\cdots$ & $x_{m+l, n}$ & $B_{t+2}$ \\
\hline$k^{\prime}$ & $r_{1}$ & $\Upsilon_{2}$ & $\cdots$ & $Y_{n-\hat{x}}$ & $\gamma_{n-\hat{x}+1}$ & $\cdots$ & $\gamma_{n}$ & $\delta$ \\
\hline
\end{tabular}

The simplex aigorithm systematically chooses palrs of varlables $\left(\eta_{I}, \xi_{J}\right)$ whose roles are to be exchanged, and then performs the exchanges, one at a time, until the set of ccefflelents $\left\{B_{i}, Y_{j}\right\}$ (within the freedom allowed by the $\ell$ equality constraints) are all non-positive. The position $(I, j)=(I, J)$ within the simplex tableau that represents the column and row varlables to be exchanged is alled the pivot. The basic transformation, or pivot step, corresponding to the elimination of $\xi_{\mathrm{J}}$ in terms of $\eta_{\mathrm{I}}$, results in the following changes in che simplex tableau:

$$
\begin{array}{ll}
\alpha_{I J}+1 / \alpha_{I J} & , 1 \neq I \\
\alpha_{1 J}+-\alpha_{1 J} / \alpha_{I J} & , j \neq J \\
\alpha_{I J}+\alpha_{I J} / \alpha_{I J} & , 1 \neq I, j \neq J, \\
\alpha_{i J}+\alpha_{1 J}-\left(\alpha_{1 J} \alpha_{I j} / \alpha_{I J}\right), & , 1, \eta_{I} .
\end{array}
$$


In the above, we read $\alpha_{1, n+1}=\beta_{1}, a_{m+i+1, j}=\gamma_{j}$, and $i_{m+i+1, n+1}=\delta$.

\section{The Simplex Procedures}

Beginning with the starting tableau, ont tirst satisfies all equality constralnts by plvoting into positions at the head of a column all those slack variables which are known to vanish. Further pivoting involving these slack variables is prohtbited. This operation is accomplished by the inftiaiization procedure, described below, which also interchanges the column orderIng so that chese slack variables which vanish a prjori occujy columns $n-i<j<n+1$. This produces the initialized tableau, upon which further proting is permitted only for $1 \leq I \leq n+i, 1 \leq J \leq a-l$.

After obtaining the initialized tableau, the algoritim sers about inding a basic feasible point, nimely a set of varlables $\left\{\xi_{j}\right.$, such that if each $\xi_{j}$ is taken to vanish, $1 \leq j \leq n-i$, then all constraints $n_{i} \geq 0$ are also satisfied. Obviously, this requlres that $B_{i} \leq 0$ tor $i \leq 1 \leq m+8$. Procadure I, outlined below, serves to find some one basic feasible point. Then, via Procedure II, the algorithm moves from one basic feasible point to another along a path of nondecreasing $w$ until the maximun feasible point, $\gamma_{j} \leq 0$ for $1 \leq f \leq \pi-\ell$, is reached, The procedures can be shown to converge In a finite number of steps in the absence of degeneracy (no $B_{1}$ vanishes). Generally, where arbitrary choices are made at indicated points in the procefures, we specify that these are to be made strictly randomly. This avoids any possibility of looping that may ocherwise occur in the presence of degeneracy. Other sequencing may, however, be more useful in large linear programming problems. ${ }^{2}$ 
LHITIALITATIUN PROCEDLRE

If $:=0$, go on to Procedure $\mathrm{I}$. If $\ell>\mathrm{n}$, the system is over-constrained, and no solution exists (in the absence of degeneracy). Otherwise, perform the initialization procedure sequentially for successively larger $k .0 \leq k \leq ;-1$, where $I=m+\ell-k$. If $B_{I}>0$, change the sign of each entry in the Ith row: $a_{I j}+-\alpha_{1 j}, \beta_{I}+-\beta_{I}$. For $\beta_{I} \leq 0$, go on to Step (1).

\section{Step (1)}

Find the algebralcally greatest $\alpha_{1 j}=\alpha_{i \omega}$, keeping track of ties. Ir $\Lambda_{I L} \leq 0$, the restrictions are incoisistent and camot be sacisfied $1 f B_{I}<0$. II $z_{I}=0$, the restriction requires that $\xi_{j}=0$ ior all $a_{I j} \neq 0$. If $a_{I \perp}>0$, ;o on to step (2).

\section{$\underline{\text { seep (2) }}$}

Among the set of $\alpha_{I j}=\alpha_{I L}$, choose $\mu=J$ for the algebraical.ly grearest $i_{\nu}$. If there are ties, any will do. Perform the pivot step, and then make the column exchang $=\alpha_{i J} \leftrightarrow \alpha_{i, n-k}, 1 \leq i \leq m+l+1$. When $k=k$, go on to l'rocedure 1 , unless $h=n$. If $h=n$, the equality constraines completely specify the problem (in the absence of degeneracy), and ro freedom to satisfy the inequality constraints exists.

PROCEUURE I

If $\left(\beta_{1} \leq 0,1 \leq 1 \leq m+\ell\right)$, go on to Procedure $I I$. Otherwise, select the greatest $1=\lambda$ for whlch $B_{1}>0$. Choose, strictly randomly, any negative coefficlent $\alpha_{\lambda j}, 1 \leq j \leq n-\ell$, determining thereby the pivot colunn $j=J$. 
(If there is no $\varepsilon_{\lambda_{j}} \sim 0$, the constraints are inconsistent and no solution exists.) Compute $\beta_{\lambda} / \alpha_{\lambda J}$ and $\beta_{1} / \alpha_{i J}$ for all $\alpha_{i J}>0, k<i \leq m+:$ Deteral ne the algebraically greatest (numertcally least) of these negative chios, selecting randouly amongst ties. This determfnes the pivor row $i=1$. Perform the pivot step, Eq. (7), and repeat Procedure $I$ as necessary uncil all $\beta_{i} \leq 0$.

PROCEDLRE II

If $\left(r_{j} \leq 0,1 \leq j \leq n-l\right)$, the problem solution is $\xi_{j}=0$ for $1 \leq j \leq n$. and $W=\delta$. Otherwise, go on to step (1).

\section{Step (1)}

Determine all $1=\lambda, 1 \leqq 1 \leq m+\ell$, for which $\beta_{\lambda}=0$. If there are none, go on to Step (2). Otherwlse determine all $j=\mu, 1 \leq j \leq n-2$, for which $Y_{\mu}>0$ and $a_{\lambda j}>0$, for those values of $\lambda$ just deteruined. If here are none, go on to step (2). Dtherwise, choose the pivot column $j=J$ randorily from among $j=\mu$, and the pivot row $i=I$ randomly from among those rows $1=\lambda$ for which $a_{\lambda J}>0$. Perform the pivot step, Eq. (7), and repeat Procedure iI as necessary until all $Y_{j} \leq 0$.

\section{Step (2)}

Choose, strictly randomly, any $Y_{f}>0$, thereby determining the pivct colunn $\mathbf{j}=\mathrm{J}$. Fompute $\beta_{i} / \alpha_{i J}$ for all $\beta_{i} \neq 0, \alpha_{i J}>0,1 \leq i \leq m+8$. (If $a_{i j} \leq 0$ for $1 \leq 1 \leq m+2, \xi_{J}$ can be increased indefinitely withour violating the constraints $\eta_{i} \geq 0$, and $W$ is unbounded.) Select the algebraically greatest (numerically least) from among the computed negative ratios $\beta_{1} / \alpha_{i J}$, choosing 
rubdunly anongst ties. This determines the plvot row $:=1$. Perform the pivul step, $k q .(7)$, and repeat. Procedure II as necessary until all $\gamma_{j} \leq 0$. (sinic Procedure 11 preserves the signs of the $\theta_{1}$, Procedure 1 is not to be used irain. Furthermore, since the pivot step replaces $\delta$ by $\varepsilon-3_{I} \gamma_{J} / \alpha_{I J}$, ind since $\bar{z}_{I} \leq 0, i_{J}>0,{ }_{I J}>0$, the value $k=\sum$ of tine basic reasible puiat sannot decrease.)

\section{User-Lavel Instructions for SIMPLEX}

Cospunicistius

\section{Calling Sequence}

Subroutine SIMPLEX is used by adding a CILI SLPPLE: card to the user's program in the appropriate place.

\section{Input}

Three parameters and the tableau must be set by the user. Mkht is the number of unknowns in the system of equalicy and Lnequality constraints. SNEQ is the number of Inequality constraints, and LEQ is the number of equality constralnts. These correspond to $n, m$, and $i$ in the theoretical discusston. These values are defined in PARAMETER statements and must be set in the source file [LY TRIX and JED (locai editors), ete.] before compflacion.

The infial tableau should be set by the user's own input or initialization routine. TABLEAU is a two-dimensional, colum.-ordered array, dimensloned (MNEQ+LEQ+1, NKWN+1), which stores the tablaau at all times during the routine. It is located in common block ARRASRL. The la t column of TABLEAL 
should contain the slack constants, $b_{i}$, Eqs. (2) and (3). The last row shnuld hold the $\Sigma_{i}$, the coefficients of the linear function to be maximized, $\sum_{i=1}^{n} c_{i} x_{i}$, Eq. (1). After the algorithm has completed, the value of the game, $W=\delta$, is the last element of the last row. The rest of the entries are the coefficients, $a_{i j}$, of the inequality constraints, $\sum_{j=1}^{n} a_{i j} x_{j} \leq b_{f}$, and the equality constraints, $\sum_{j=1} a_{i j} x_{j}=b_{i}$. The equality constraints must be glaced af ter the jnequality constraints in the tableau. For details of the tableau, see Owen. ${ }^{1}$

There are a?so some variables the user may set to make use of some options, nut these may be ignored if the defauits produce the required results.

- NCYCSTP is the number of times subrout1nes PRCDR1 or PRCDR2 w111 execute their main loops without creating an exit condition. It is set as $\mathbf{3}$ default to 200 .

- NMBSC, NMNBSC are the names of the basic and non-basic variables to be printed on output in an AG format fleld. As defaults, the basic variables are called "ETA", the non-basic " $\mathrm{x}$ ".

- 2EROFAC is a fraction which, when multiplied by the largest absolute value of an entry in the infial tableau, gives a relative zero test. It is set to 1. $\mathrm{E}-10$.

- IPRNTFLG determines the amount of $\mathrm{I} / 0$ desired from the routine. ( 0 - no output, 1 - some output after the solution is found, 2 - the tableau is printed every pivot.) The default is 0. LUN is the logical unit number for printed output. Default is 10 .

\section{Output}

All output values returned to the calling program are the global variables in com...: blocks CNSTSPP and ARRASMP. The solution of the prograin is In array $x$ and the value of the game is in $W$. NERR ahould always be checked 
upon return for errors. A zero value for NERR indicates a nomal return. An error condition will aluavs produce output on logical unit number LtN, which must be assigned to a disk file.

During a normal execution of the routine, when IPRNTFLG is zero, no output will be printed. If IPRNTFLG is set to one, the solution, $X(I)$, and the value of the game will be printed when a solution is found, Also, the initially basic and non-basic variabies with zero values will be 1 isted, and the variables with non-zero values will be listed along with their values. When IFRNTFLG is set to two, the tableat is printed every pivot cycle along with some other information. With this option, the code is I/O bound; ti runs much more slowly.

\section{Error Returns}

After a call to SIMPLEX, a non-zero value for NERR indicates an error retura.

- NERR $=1:$ The constraints are inconsistent. There is a row that ends with a positive entry and has only non-negative entries.

- NERR $=2:$ The problem is unbounded. There is a column with a positive last entry, and all the remalning entries are non-positive.

- NERR $=3:$ This flag means that the program has fallen through loop SLI in subroucine STEPl without finding any elements available for choice as a pivot. This should not happen normally because the tests previous to this loop should assure that an appropriate element exists.

- $\quad$ NERR = 4: Subroutine PRCDRl has pivoted NCYCSTP times withouc making the last column negative, except for the last entry. 
NERR $=5:$ Subroutine PRCDR2 has pivoted the tableau NCYCSTP times without making the last row negative, except for the entry. NERR $=6:$ The systiem is over-constralned. The slack varlables for equality constraints must be equal to zero; therefore, the slack variables heading the row of an equality constraint must be plvoted to the head of a column and kept there. Since there are fewer columns than equality constraints, i.e., $\ell>n$, this cannot be done. NERR = 7: The problem ts specified by equality constraints. Since $\ell=n$, there are the same number of columns as equality constraints. Thus, once the equality constraints are pivoted up, no more mantpulation can be done on the tableau.

- $\quad$ NERR = 8: No elenent of an equality constraint was positive when the corresponding $B$ was negative. Thus, the restrictions are inconsistent and cannot be satisfied.

- NERR = 9: Same as 8, except $\beta$ was zero. Hence, the restrictions can be satisfied only $i \bar{i} \xi_{j}=0$ for all non-vanishing $\alpha_{I j}$.

- NERR = 10: Subroutine PIVOT was called to pivot on a zero tableau element.

- NERR = II: The error routine was called improperly; 1.e., the error number was not between 1 and 10, inclusive.

\section{Common Blocks}

- CNSTSMP: This stores all global scalar variables (non-parameters) for SIMPLEX. For additional information, see cliche SMPCLCH (in Appendix A).

- ARRASMP: This stores all global arrays for SMPLEX. See cliclie SMPCLCH (in Appendix A) . 
Fluw Diagram

A Elow dlagran for the SIMPLEX routine is given in Fig. 1.

RESTRICTIONS

This routine becomes very siow if a large tableau is frequently output. If IPRATELG is set to two, the program becomes $I / 0$ bound. This can be helped by increasing the output buffer size (to $10004_{8}$, or $20004_{8}$ ), but this option should be used only on small problems unless necessary. Possible error returns can be avoided if the tableau to be solved has more unknowns than equalicy constraints and if trivial constraints (all the coeffictents are zero) are eliminated.

The only definite restriction on the size of the tableau is that it must fit into SCM on the CDC 7600 along with the code for SIMPLEX and the user's code. If this becomes a restriction, the code could be set up so that the tableau is placed in CDC 7600 large-core memory. Some reprogramning would be necessary, and slower execution would be expected.

EXTERNAL NAMES

- Subroutines supplied: STMPLEX, SETVAL, INITIALIZE, PREQJ, PRCDR1, PRCDR2, OUTSOLN, PIVOT, RANDOM, STEP1, STEP2, OUTX, ERRORPR, PRINTTAB.

- LIbraries required: $\operatorname{ORDERLIB}(I / 0, \mathrm{RNFL})$.

- Common blocks: CNSTSMP, ARRASMP. 


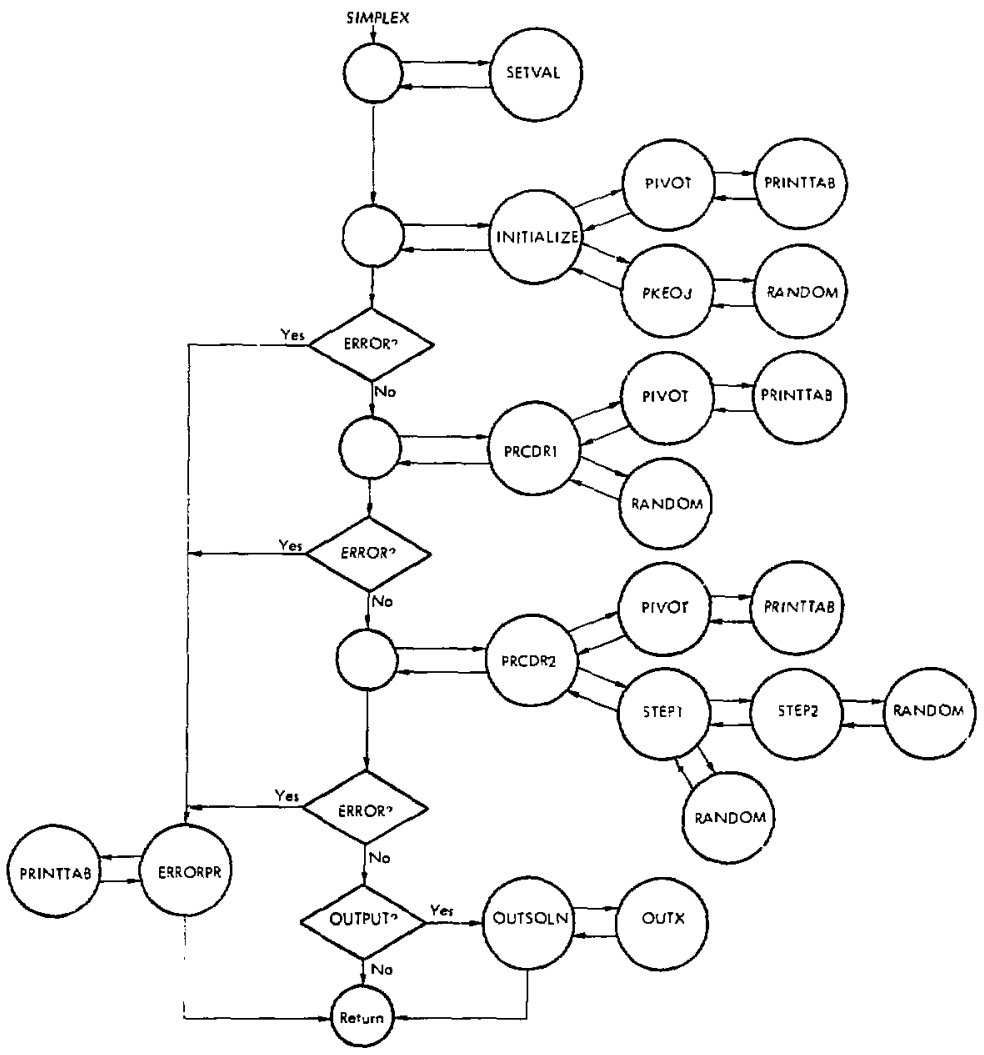

F1g. 1. Subroutine flow in SIMPLEX. Most of the subroutine calls are controlled by tests, so that the actual flow of the program will depend upon the inftial and current states. 
SPECIAL INSTRUCTIONS

Care should be taken in combining user's global declarations with the routine's global declarations, which are in cliche SMPCLCH, to avoid overlapping common blocks.

In some situations, ZEROFAC may have to be changed in order to provide correct differentiation between small but significant values and numbers which should be zero but which due to roundoff are very small numbers.

Equality constraints can be handled in a number of ways by the simplex algorithm. Equality constraints can efther be placed in the tableau after inequality constraints, or each equality can be replaced by two inequalities; i.e., $a+b=c$ is equivalent to $a+b \leq c,-a-b \leq-c$. Depending on the particular problem being solved, the representation of the equality constraints may make a sfgnificant difference in the program performarce. For the neutral beam injection test problem discussed in Secion 4 of this report, the solution was found in 50 pivots, with the equalicy constraint bcing placed after the inequality constraints. (In this case, $n=40$ gave a tableau dimensioned 42 by 41 .) When the equality constraint was replaced by two Inequalities placed alter the normal inequality constraints, the tableau (now 43 by 41 ) was solved in 56 pivots. By placing the two inequalities before the normal inequality constraints, the result was found in 25 pivots. The best method of representing the squality constraints will vary from one type of problem to another, and in some cases there will be no significant difference between methods. However, a little experimentation may determine a superfor means of representing the equality constraints that will cause signficant time saving in the solution of large problems. 
AVAILABILITY

- Machines: CDC 7600

- Size: Subroutine STMPLEX contains 357 LRLTRAN source lines. The program that tests SIMPLEX contains 207 source lines.

- Timing and optimization: Each cycle (pivot element selection and pivot) takes about 0.02 second when no $I / 0$ is done in the cycle. If the tableau for a given problem is to be printed eften, the output should probably be optimized. This could involve just setting the ORDERLIB output buffer size to a larger value, e.g., $2004_{8}+20004_{8}$. If more speed is required, subroutine PRINTTAB will probably have to be reworked. If the computational portions of the routine need more speed, BEGLMAP, a local timing routine, ${ }^{3}$ indicates that $20-25 \%$ of the CPU time is spent in Loop NXTI in subroutine PIVOT when SIMPLEX is run creating some output (IPRNTFLG=1). Efforts to Itiprove speed should probably begin here.

- Accuracy: For the test case in Section 4 with $N=40$, the error in the numerical value of the game, compared to the analytic result, was $0.232 \%$, With $\mathrm{N}=100$ over the same interval $(2-1 / 2$ times as fine a mesh), the error was $0.0596 \%$.

\section{PORTABILITY}

This program is written in LRLTRAN, not in FORTRAN. There are a number of differences between the SIMPLEX code as written and FORTRAN. These easily remedied differen:es are:

- SIMPLEX uses alphabetic rather than numeric statement labels in all situations except format statements. 
- In SLuplix, the sign of DO loop increments is not always positive (thus allowing the luop to be swept "downward"). Also, the expressions for the do loop limits are sometimes more complicated than FORTRAN allows.

- Array and dimension indexes in SIMPLEX are sometimes more conplicated expressions than FORTRAN allows.

- Variable and subroutine names containing more than six characters have been used,

- Hollerith information is Iisted within double quotes ("...") in SIMPLEX rather than the standard nH....

- Parentheses rather than slashes are used in the DATA declaration.

- The variable format, using *, used in subroutine PRINTTAB, is peculfar to Lawrence Livermore Laboratory.

- The cliche definition makes use of the LRLTRAN macro facility to accomplish global declarations wich one statement. The statenent, USE SAirCLCH, causes the compiler to insert $a_{+} l$ the LRLTRAN statements between CLICHE SMPCLCH and ENDCLICHE into the code at that point.

- The parameter statement, unavailable in fortRan, deíines a constant value which is not allowed to be changed (the compiler creates 3 1iteral).

- The routine RNFL, used in subroutine RANDOM, is part of the LRLTRAN

library. It wil1 need to be replaced by a local raidom generator. RANDOM may have to be reprogrammed to produce the required rasults with a different random number generator.

For variable definitions, details of the code, etc., see the listing in Appendix A. 


\section{Examples}

We have outlined procedures and a numerical code for solution of the 1Inear programing problem to find the maximum $W$ satisfying Eqs. (1) through (3). This code has been used by Hall, et al, 4 to find the optimum distribution of injectors for the problem of neutral beam injection of a plasma in magnetic mirror traps. In this problem, one seeks to maximize the pressure of the contained plasma for a given Injected current, and In a certain discrete representation

$$
\begin{aligned}
& w=\sum_{j=1}^{n} x_{j} \ln v_{j}, \\
& \sum_{j=1}^{n} x_{j} v_{i j} \leq 1, \\
& \sum_{j=1}^{n} x_{j}=1 / T(R, a, 1),
\end{aligned}
$$

where $R$ and a are constants, $l<a<R$, and $v_{j}=1 / 2+(R-1)(j-1) / n, \quad j=1,2, \ldots, n$,

$T(R, \rho, v)=\frac{3}{B}(R \rho)^{1 / 2}\left\{(R+\rho) \tanh ^{-1}\left[(\rho-v)^{1 / 2}(R-v)^{-1 / 2}\right]\right.$

$$
v_{i j}= \begin{cases}T\left(R, v_{j}, 1\right)-T\left(R, v_{j}, v_{i}\right), & 1<j, \\ T\left(R, v_{j}, 1\right) & , 1 \geq 1 .\end{cases}
$$

When $R \propto 3$ and $a=2$, we found the algortthm converged in 24 steps of the simplex procedure when $n=40$, and the last restriction, Eq. (8), was taken with = replaced by $\leq$. Use of the equality or the equivalent double inequalicy increased the number of steps as discussed on page 13. The analytic solution 
to this problem was also found by Hall, et al., and we Include as Append1x B the set of graphs showing the convergence of the simplex algortthm to the analytic solution. We also solved this problem for $n=10$ and $n=100$, and Fig. 2 compares the final results for these cases.

Several ather test problenıs, caken from basic linear programing texts, have been solved successfully. An example is Orchard-Hays widget problem. 5 In this problem, the profits of a widget manufacturer are related to inventory and labor costs and give rise to the profit function

$$
w=5.40 x_{1}+7.30 x_{2}+12.96 x_{3}-6 x_{4}-9 x_{5}-800,
$$

subject to the constraints

$$
\begin{array}{ll}
0.50 x_{1}+0.60 x_{3}-x_{4} & \leq 80 \\
0.25 x_{1}+0.50 x_{2}+0.60 x_{3}-x_{5} & \leq 40 \\
-x_{1}+x_{2} & \leq 0 \\
100 \leq x_{1} \leq 150 & \\
x_{4} \leq 20 & \\
x_{5} \leq 10 .
\end{array}
$$

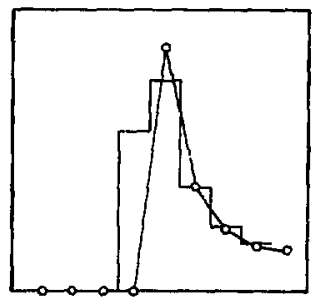

$\mathbf{n}=10$

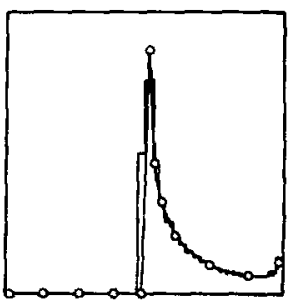

$n=40$

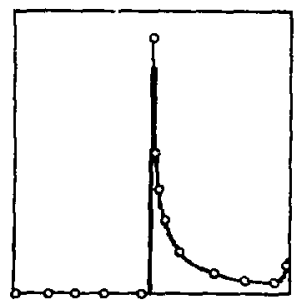

$n=100$

Fig. 2. Comparison of the final results of the SIMPLEX golution of che neutral injection problem for $n=10, n=40$, and $n \times 100$. The solid curve Is the analytic solution (on an arbitrary scale), and the bar diagrans give the numerical approximations. 
The range of $x_{1}$ is equivalent to two inequalities, $x_{1} \leq 150,-x_{1} \leq-100$, and has been expressed in the SIMPLEX tableau, T1.

$\begin{array}{rcccccc} & x_{1} & x_{2} & x_{3} & x_{4} & x_{5} & 1 \\ -n_{1} & 0.500 & 0.000 & 0.600 & -1.000 & 0.000 & -80.000 \\ -n_{2} & 0.250 & 0.500 & 0.600 & 0.000 & -1.000 & -40.000 \\ -n_{3} & -1.000 & 1.000 & 0.000 & 0.000 & 0.000 & 0.000 \\ -n_{4} & 1.000 & 0.000 & 0.000 & 0.000 & 0.000 & -150.000 \\ -n_{5} & -1.000 & 0.000 & 0.000 & 0.000 & 0.000 & 100.000 \\ -n_{6} & 0.000 & 0.000 & 0.000 & 1.000 & 0.000 & -20.000 \\ -n_{7} & 0.000 & 0.000 & 0.000 & 0.000 & 1.000 & -10.000 \\ w & 5.400 & 7.300 & 12.960 & -6.000 & -9.000 & -800.000\end{array}$

Solution of this problem by SIMPLEX produed the final tableau, I2.

\begin{tabular}{|c|c|c|c|c|c|c|c|}
\hline & & $n_{5}$ & $x_{2}$ & $n_{2}$ & $x_{4}$ & $n_{7}$ & 1 \\
\hline & $-n_{1}$ & 0.250 & -0.500 & -1.000 & -1.000 & -1.000 & -5.000 \\
\hline & $-x_{3}$ & 0.417 & 0.833 & 1.667 & 0.000 & 1.667 & -41.667 \\
\hline & $-n_{3}$ & -1.000 & 1.000 & 0.000 & 0.000 & 0.000 & -100.000 \\
\hline $\mathrm{T} 2:$ & $-\pi_{4}$ & 1.000 & 0.000 & 0.000 & 0.000 & 0.000 & -50.000 \\
\hline & $-x_{1}$ & -1.000 & 0.000 & 0.000 & 0.000 & 0.000 & -100.000 \\
\hline & $-n_{6}$ & 0.000 & 0.000 & 0.000 & 1.000 & 0.000 & -20.000 \\
\hline & $-x_{5}$ & 0.000 & 0.000 & 0.000 & 0.000 & 1.000 & -10.000 \\
\hline & W & 0.000 & -3.500 & -21.600 & -6.000 & -12.600 & 190.000 \\
\hline
\end{tabular}

The value of the game is $W=190$, the result found by orchard-Hays. The detalled result difers from Orchard-Hays, iwover, who found (upon conversion to our notation) the final tableau, T3. 


\begin{tabular}{|c|c|c|c|c|c|c|c|}
\hline & & $\mathrm{T}_{1}$ & $x_{2}$ & $\Pi_{2}$ & $x_{4}$ & $r_{7}$ & 1 \\
\hline & $-n_{5}$ & 4.000 & -2.000 & -4.000 & -4.000 & -4.000 & -20.000 \\
\hline & $-x_{3}$ & -1.667 & 1.667 & 3.333 & 1.667 & 3.333 & -33.333 \\
\hline & $-n_{j}$ & 4.000 & -1.000 & -4.000 & -4.000 & -4.000 & -120.000 \\
\hline T3: & $-\eta_{4}$ & -4.000 & 2.000 & 4.000 & 4.000 & 4.000 & -30.000 \\
\hline & $-x_{1}$ & 4.000 & -2.000 & -4.000 & -4.000 & -4.000 & -120.000 \\
\hline & $-n_{6}$ & 0.000 & 0.000 & 0.000 & 1.000 & 0.000 & -20.000 \\
\hline & $-x_{5}$ & 0.000 & 0.000 & 0.000 & 0.000 & 1.000 & -10.000 \\
\hline & W & 0.000 & -3.500 & -21.600 & -6.000 & -12.600 & 190.000 \\
\hline
\end{tabular}

Thus, we have an example of a problem with multiple solutions. The coefflcient of $n_{5}$ in the expression for $W$ from tableau $T 2$ is zero, so that any pivot in tie first colum (allowable only if $a_{I J} \neq 0$ ) will leave the value $\delta$ unchanged. Just as in Procedure 1I, therefore, we may always pivot in the row for which $\dot{s}_{i j}>0$ and $\beta_{i} / \alpha_{i J}$ is maximal (least negative) to get another feasible solution. Since $J=1$, this pivot point is $(I, J)=(1,1)$, and performance of the pivot step produces the equal-vaiue orchard-Hays tableav, I3.

Degeneracies occur whenever a zero value of $\beta_{1}$ or $\gamma_{f}$ artses. The procedures have been set up to avold interminable looping when zeros of $\beta_{1}$ exist, and these were discussed above. If all solutions $W=W_{\text {max }}$ are required, it is a sigple matter to add the additional progranming involving pivoting elther in the rows with $B_{i}=0$ or in the colunns with $\gamma_{j}=0$ in order to produce this set. 


\section{References}

1. Gulllerm Ower, Game Theory ( $H$. B. Saunders Co., Phtladelphia, 1968).

2. Will 1am Orchard-Hays, Advanced Linear Programming Computing Techniques (McGraw-Hi11, New York, 1968).

3. L. J. Sloan, BEGIMMAP: A 'rogram that Analyses Computer Programs, Lawrence Livermore Laboratory Rept. VCID-30091 (1974).

4. L. S. HalI, E. B. Hooper, Jr., and W. A. Newcomb, Optimal Injection cf Beams In a Mirror Well, Lawrence Livermore Laboratory Rept. UCRL-75561 (1975).

5. William Orchard-Ha;s, 20c. 소․, Sec, 3.5 . 


\section{Appendix A}

Code Listing of SIMPLEX (including routines used for the neutral injection problem). 


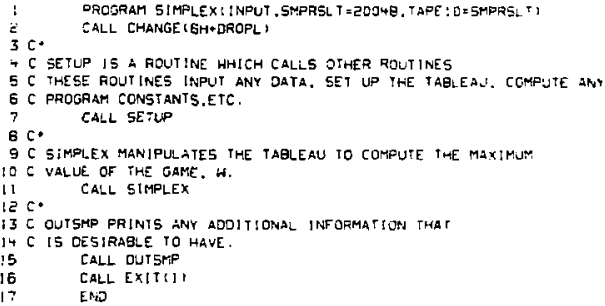

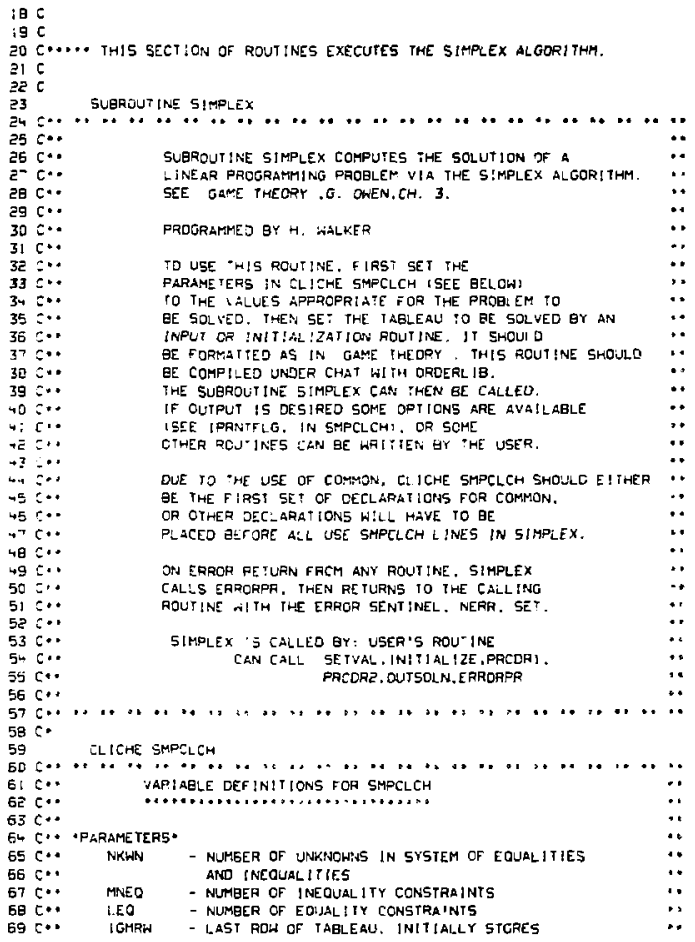




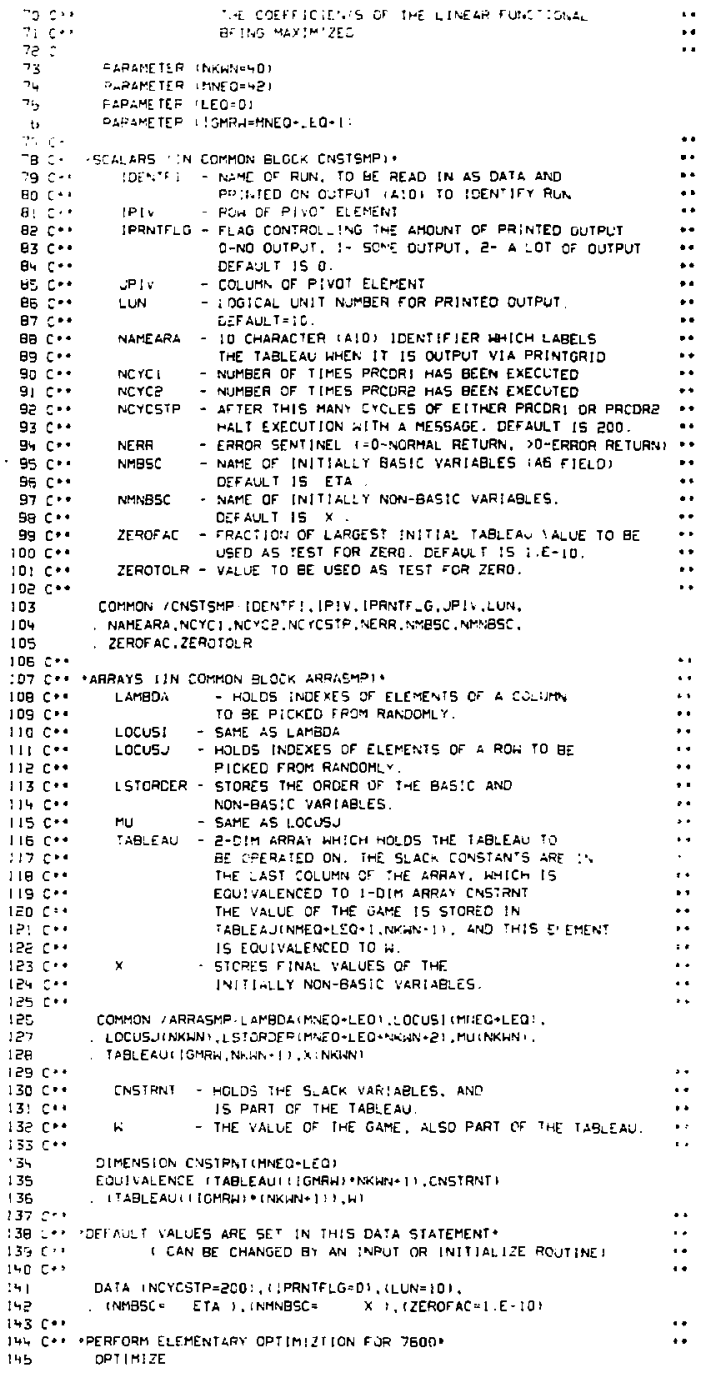



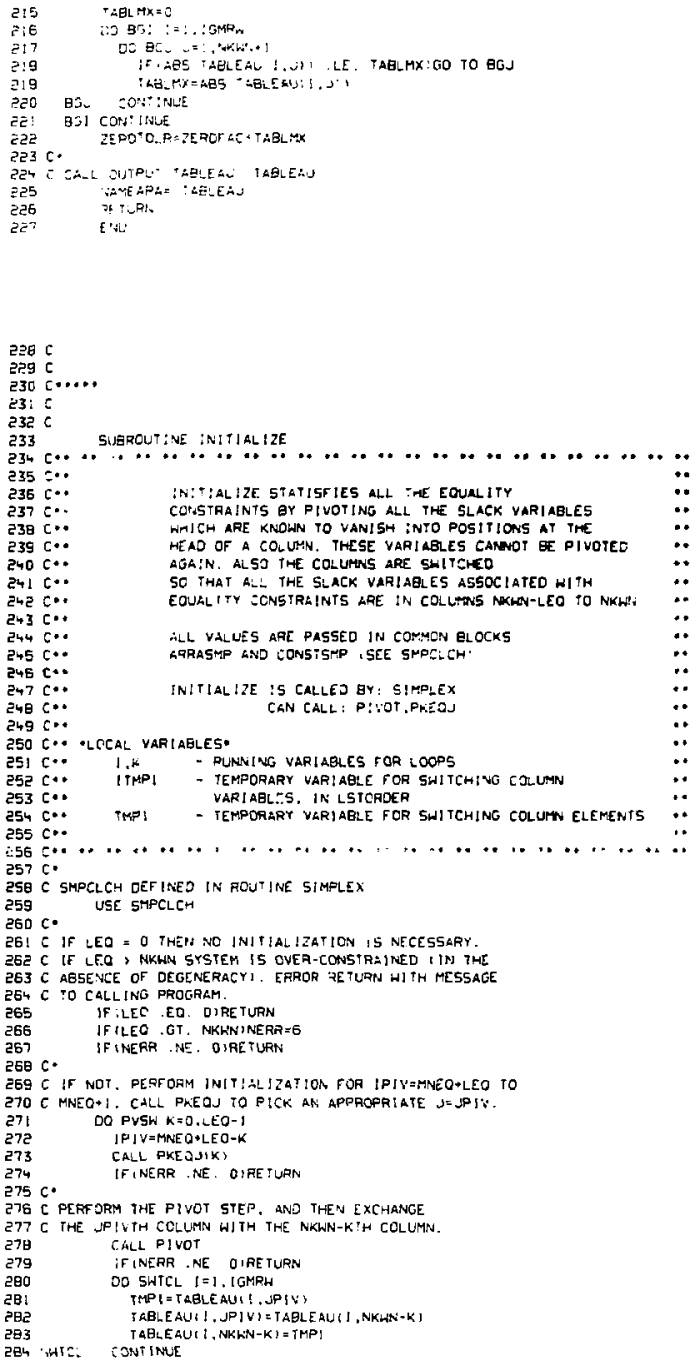

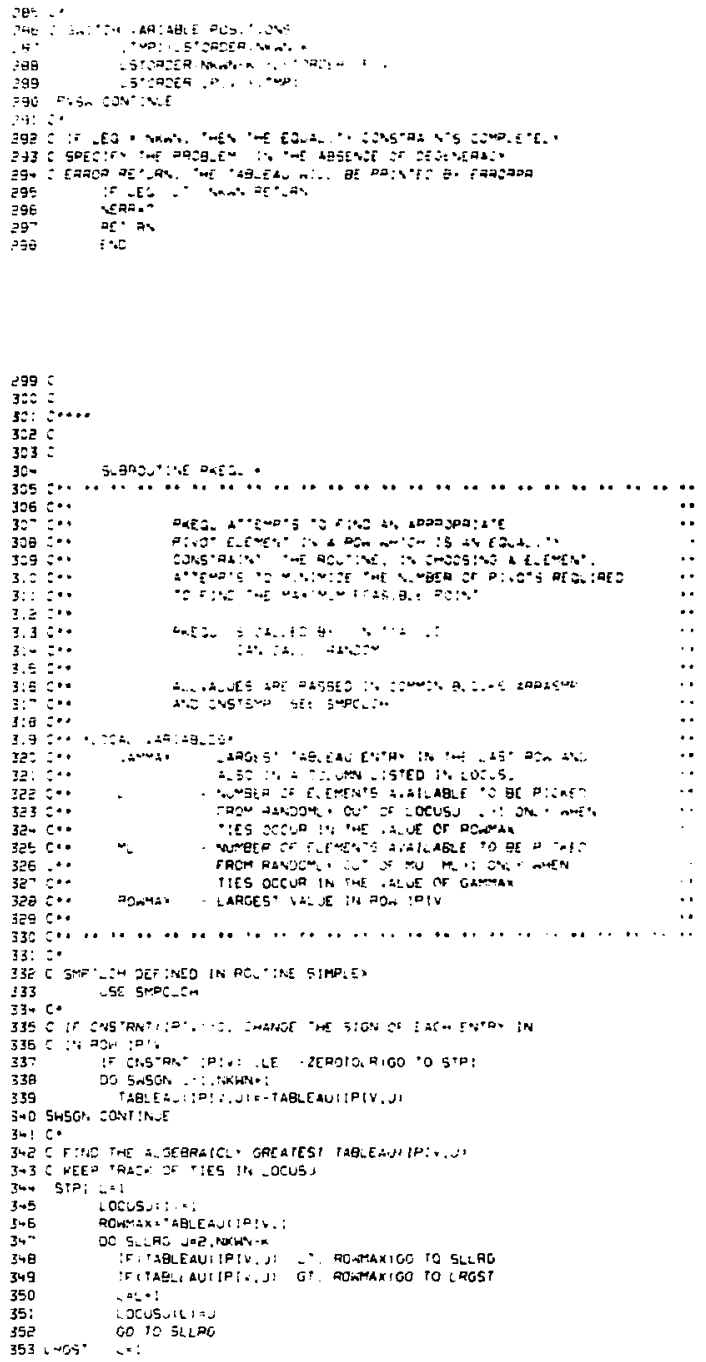

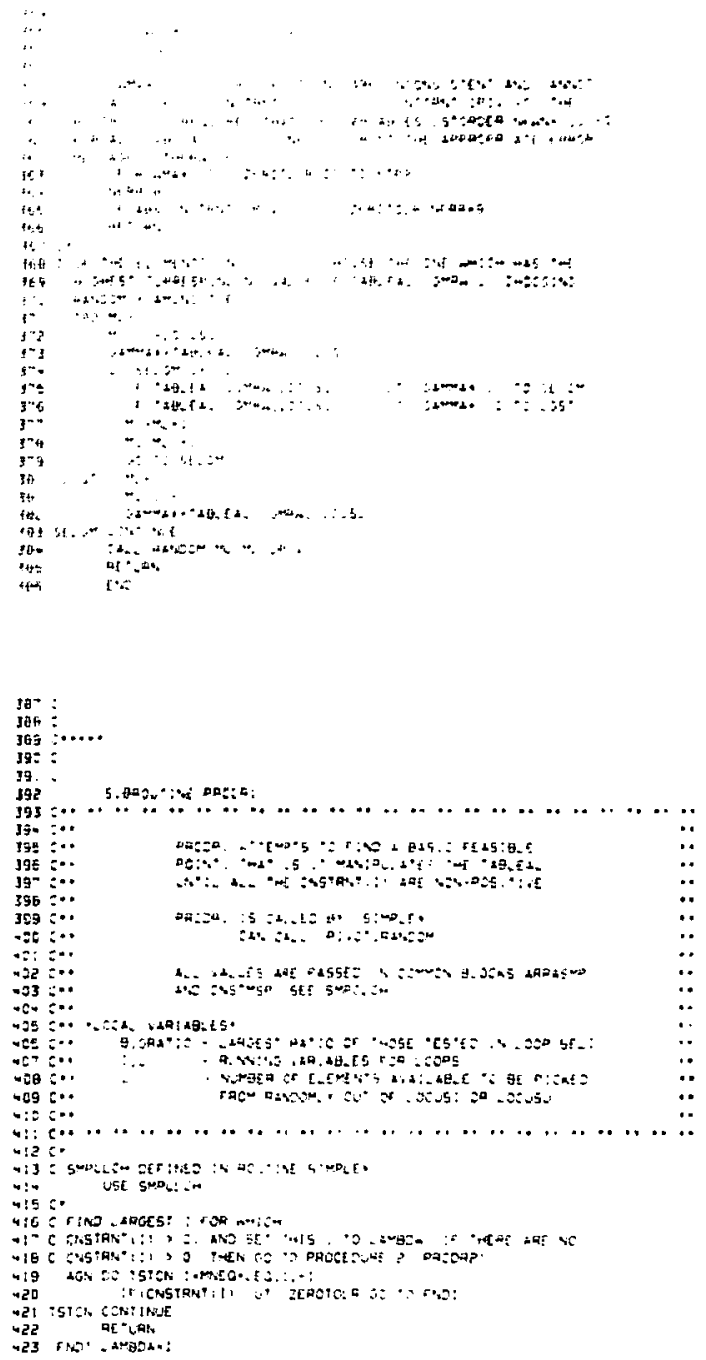


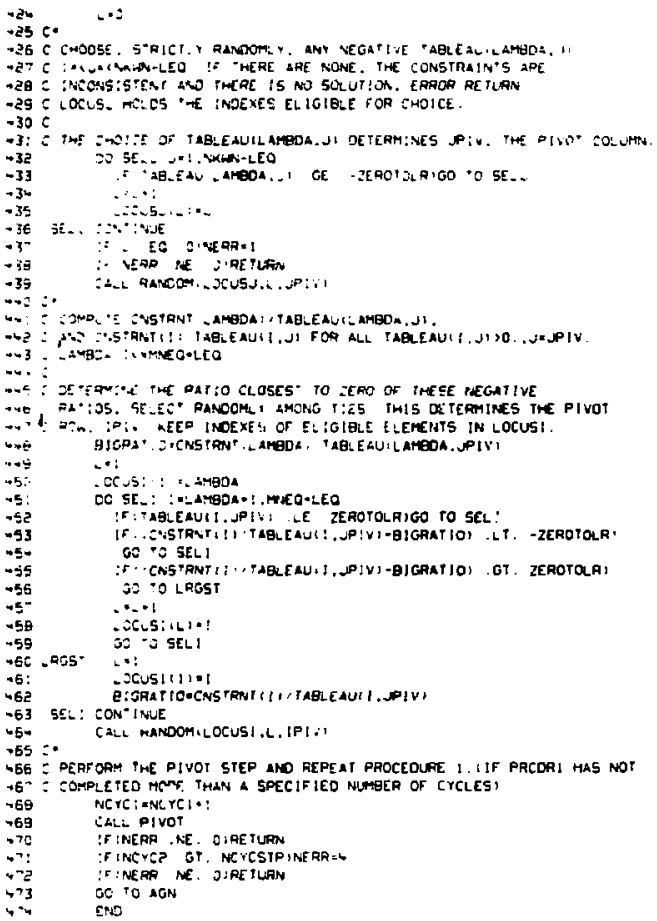

PREDRE RTTEMPTS TO 5 IMO A MAXIMUM EEASIQLE POINT, I.E. IT maNIPULATES THE TAELEAU UNTIL all OF THE LAST ROH OF THE TABLEAU, EXCEPT THE LAST ELEMENT, IS MON.POSI TIVE

pacorz IS CALLEo gr: SIMPLEX CAN CALL: PIYOT.SIEP!

ALL VALUES ARE PASSED IN CMHON BLOCKS ARRASMP CNSTSMP ISEE SHPCLCMI 


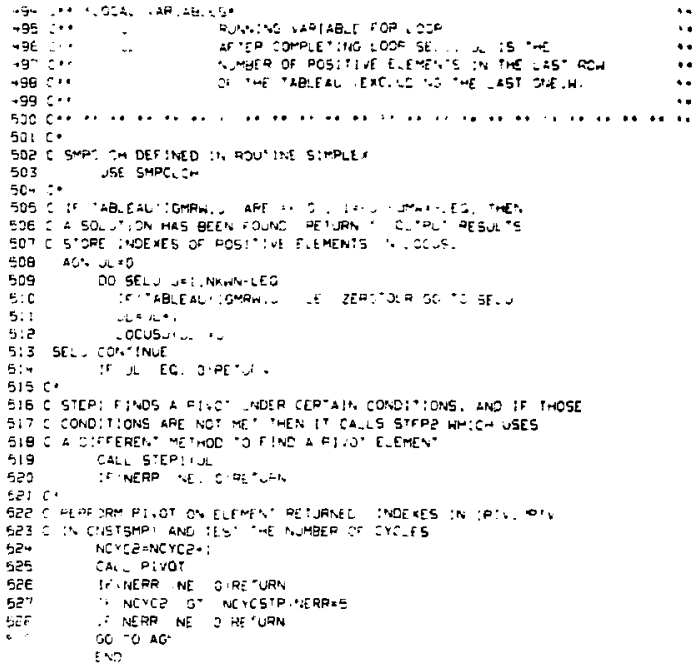

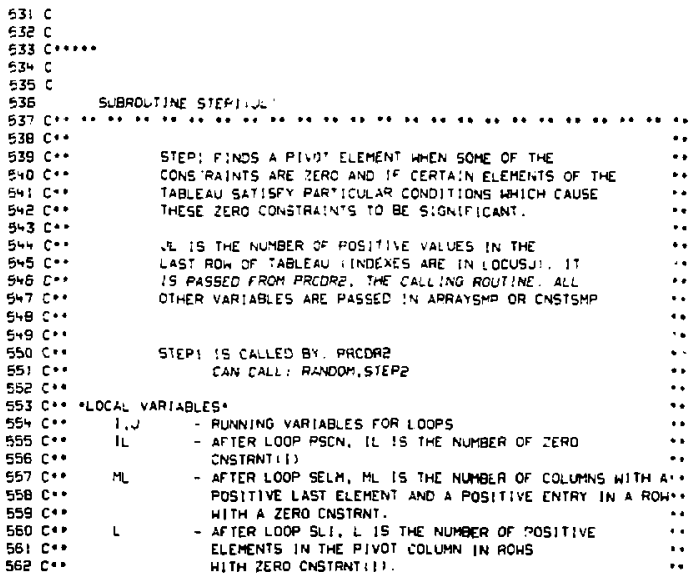




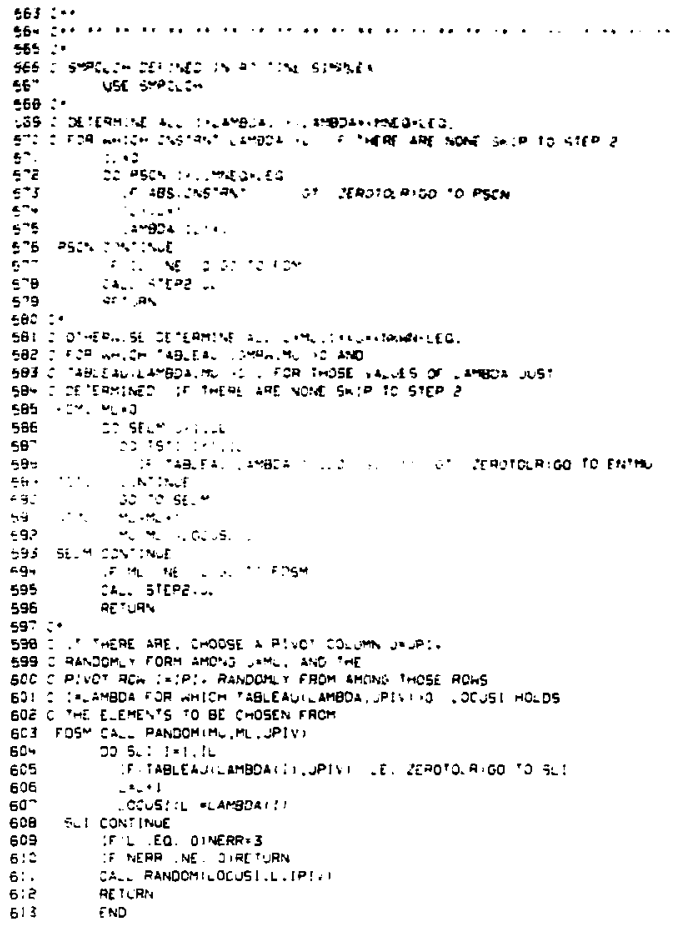

618 

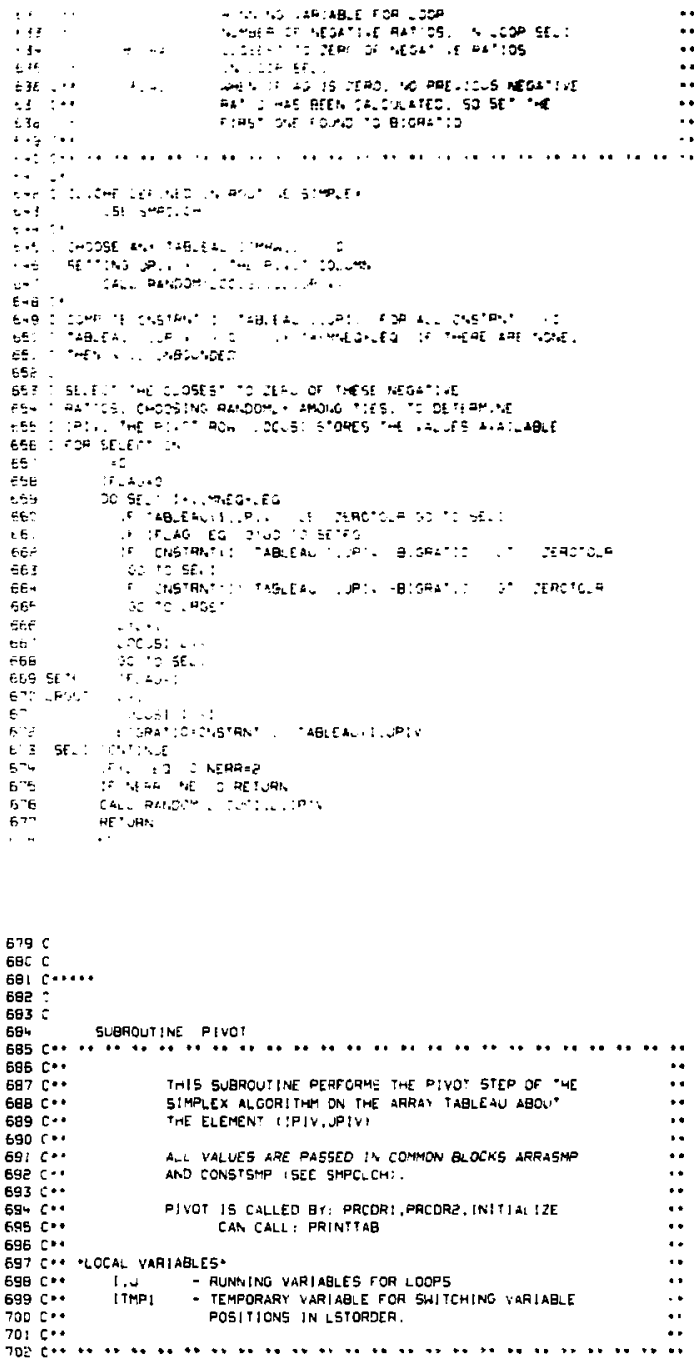

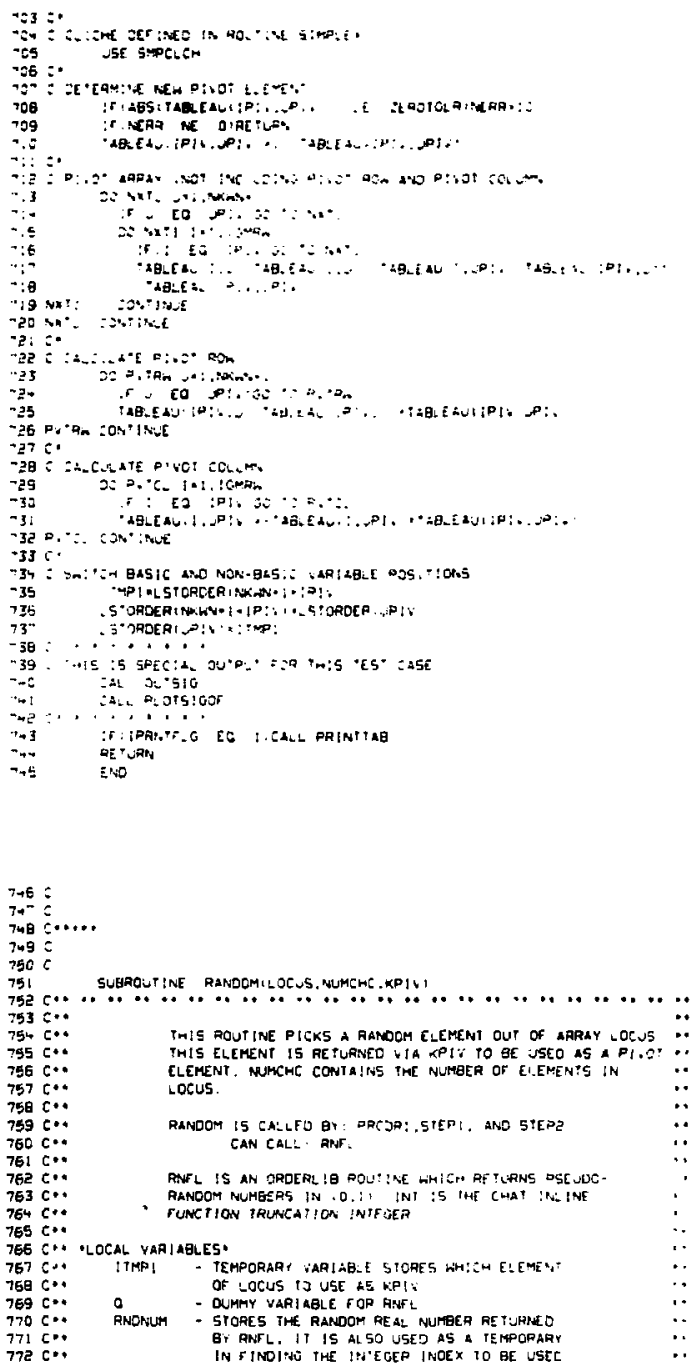

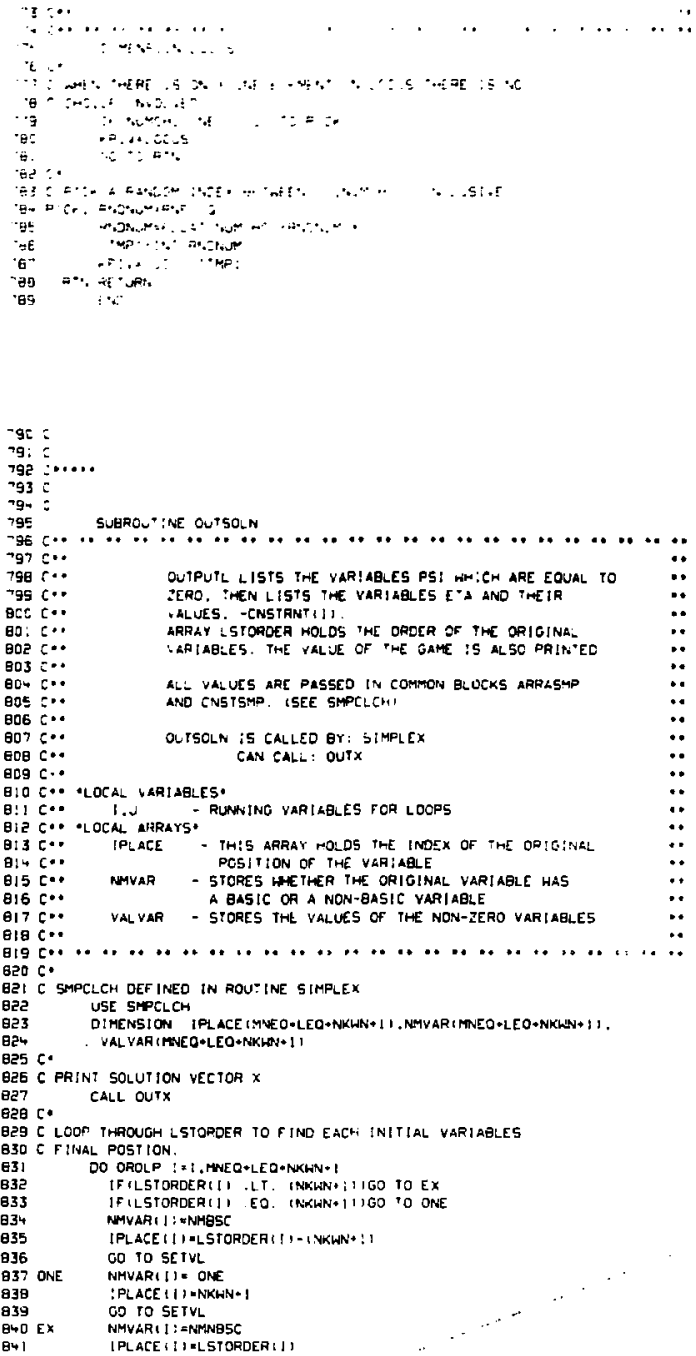

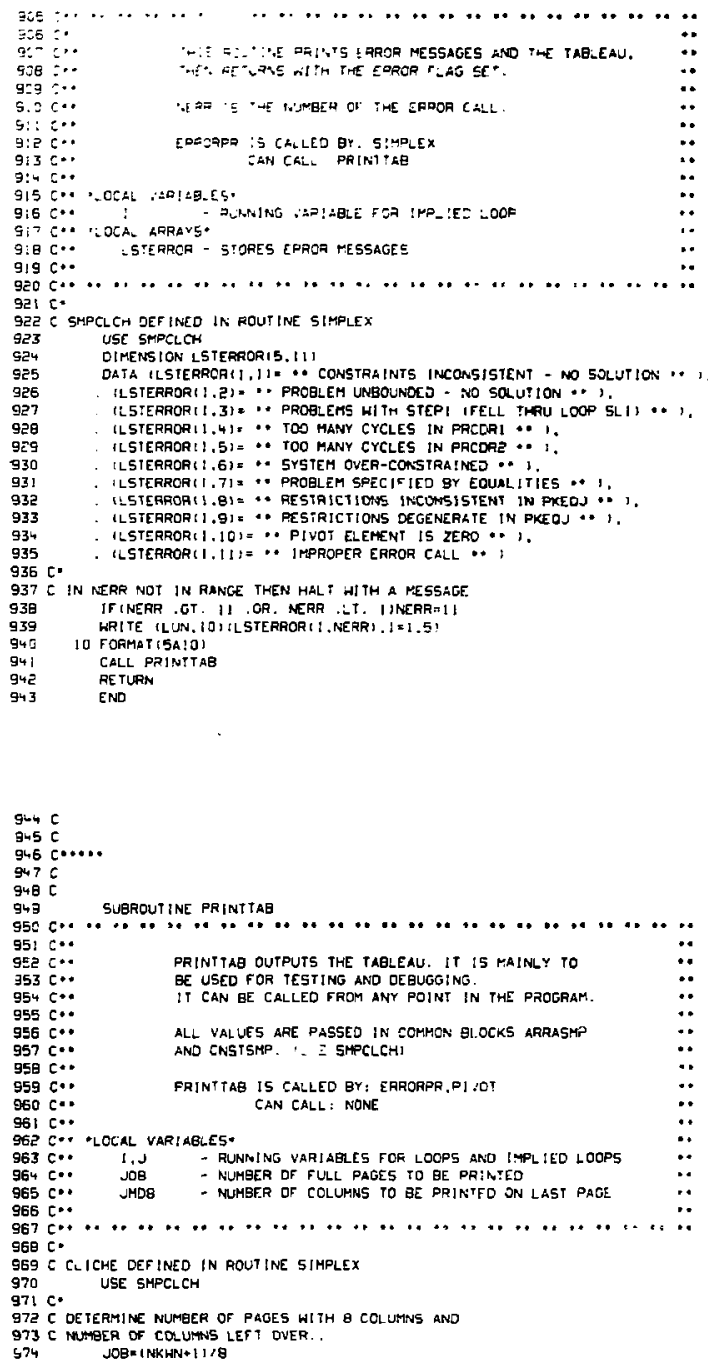


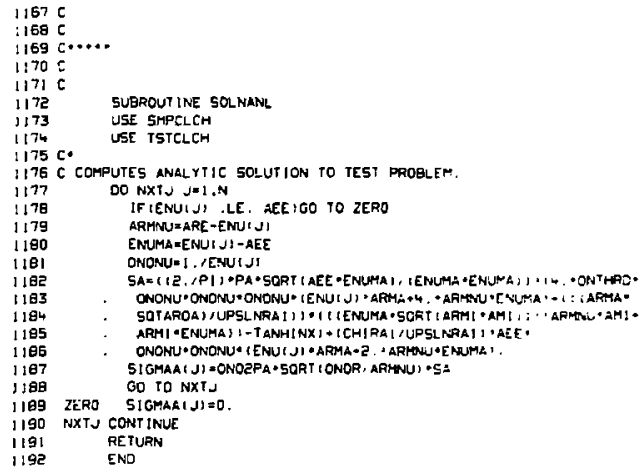

$1193 \mathrm{C}$

$: 194 \mathrm{C}$

$1195 \mathrm{C} \cdots+\cdots$

$1196 \mathrm{C}$

1997

1190

$1199 \mathrm{C} \cdot$

1200 C THIS ROUTINE PRINTS THE ANALYTIC SOLUTION.

$120:$ USE SMPCLCH

1205 USE ISTCLCH

1203 HRITE ILUN, ID)

$1204 \quad 10$ FORMATI/, SIGHAAT J) $=$ ?

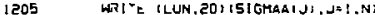

1206 20 FORMATIBTEI5.6I,

1207 RETURN

1200

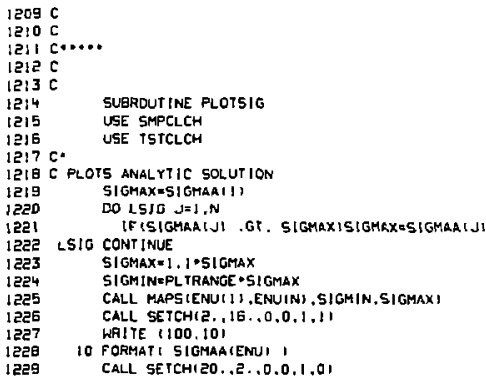


1230

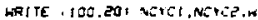

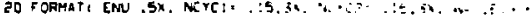

CALL TRACEEGIHA.ENL. SISMAA.V

CALL FRAME

RE TUPN

ENO

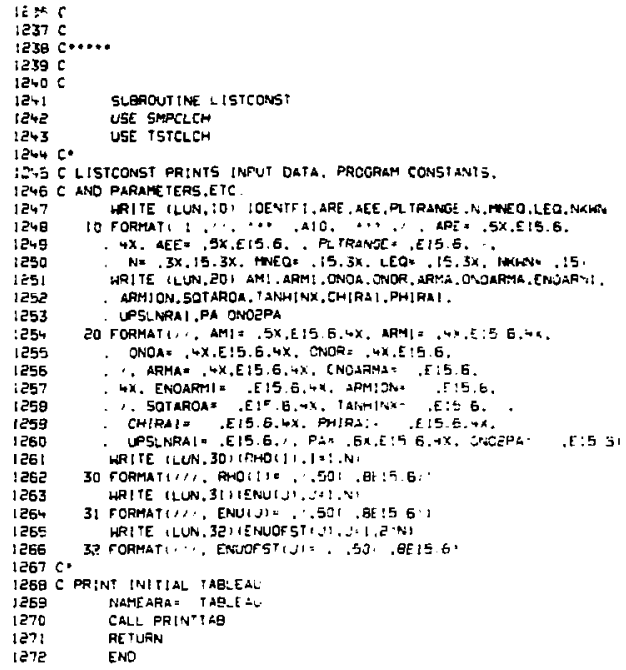

1260 - PERF ORMS MPPROPRIATE OUTPUT FOR THE TEST PROBLEM.

IJB! USE SMPCLCH

I $28 \mathrm{~A}$ USE ISTCLEH

teB3 CALL LISTCONST

I2B4 CALL OUTSIG

IEES GALL OUTSITA

lads CALL PLOTSIGOF

I2E7 CALL FLOTE

1 JBG RETURN

t 289 END 


\section{Appendix B}

The Sequence of Iterations Showing the Convergence of the Simplex Algorithm for $n=40$ in the Neutral Injection Problem. (The solid curve is the analytic result. The vertical scale is arbitrary and is set by the computer. Relative values may be determined by the height of the analytic curve.) 


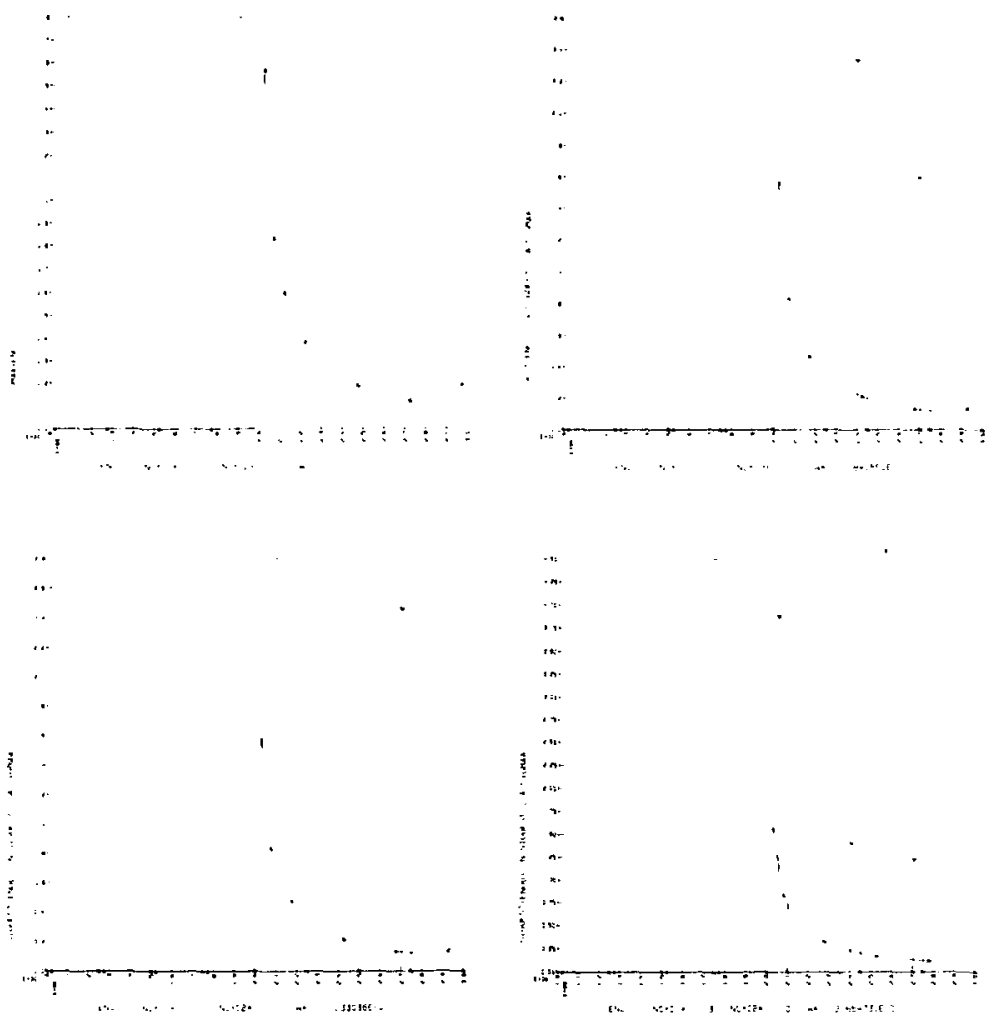



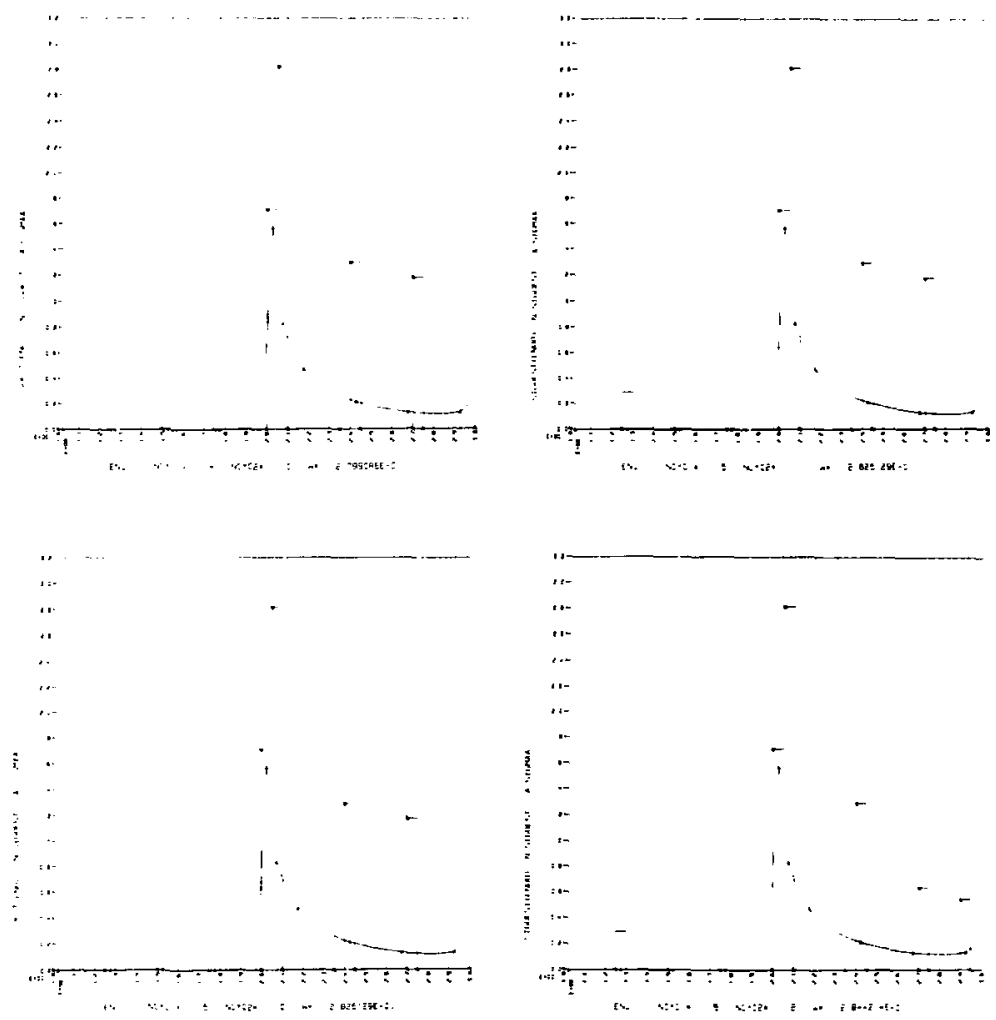


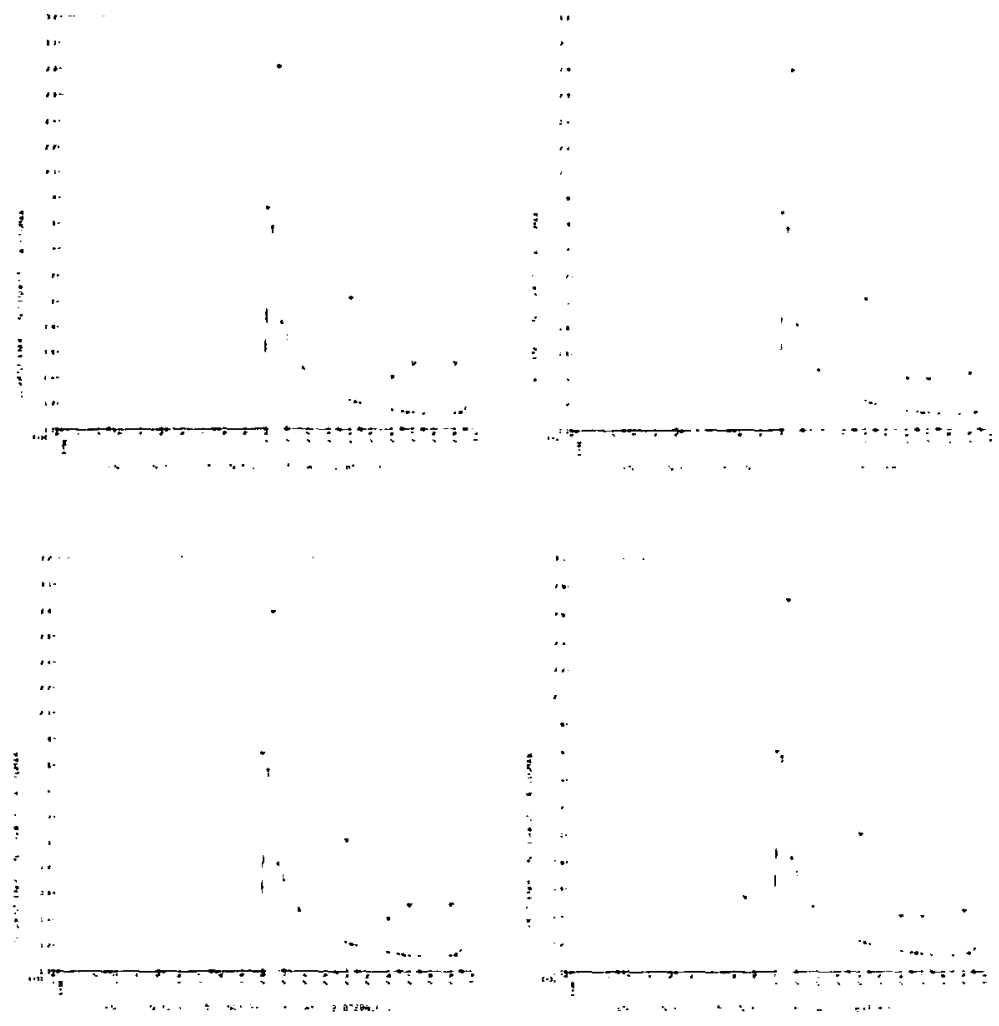



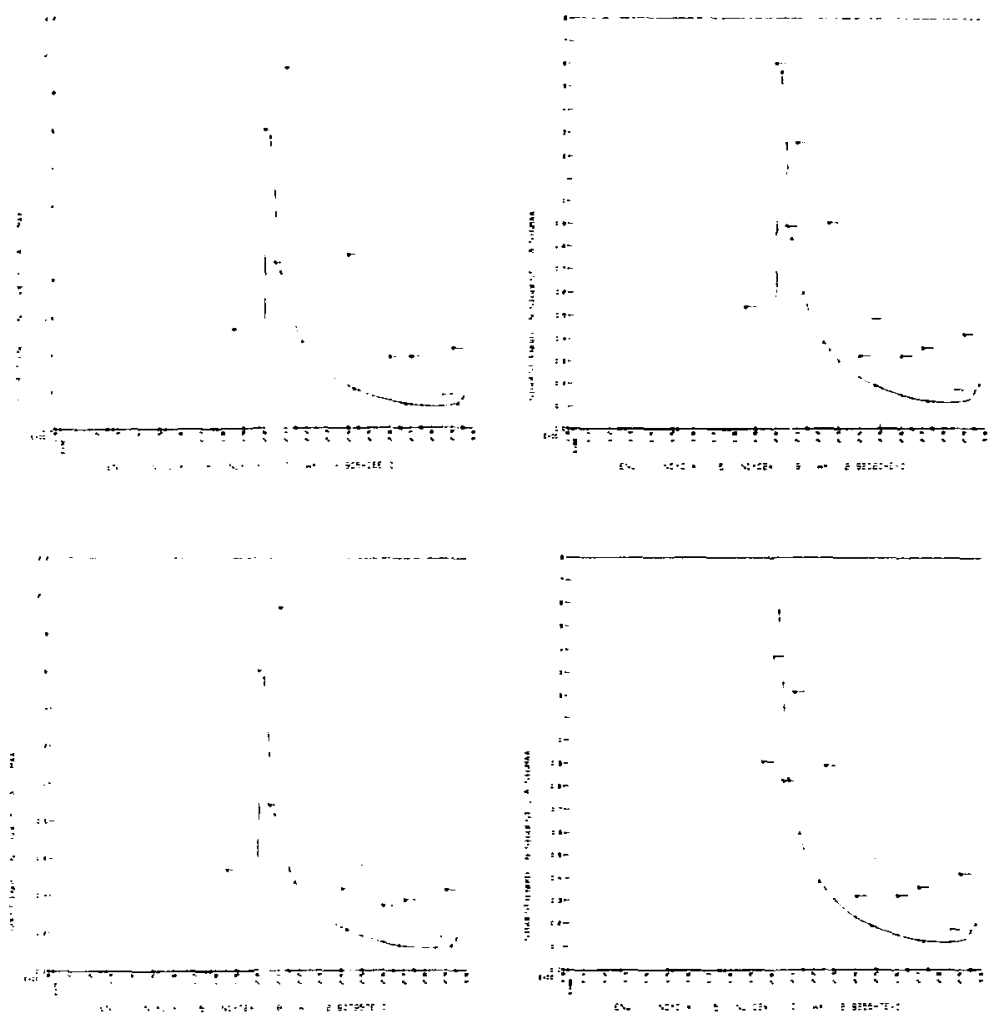

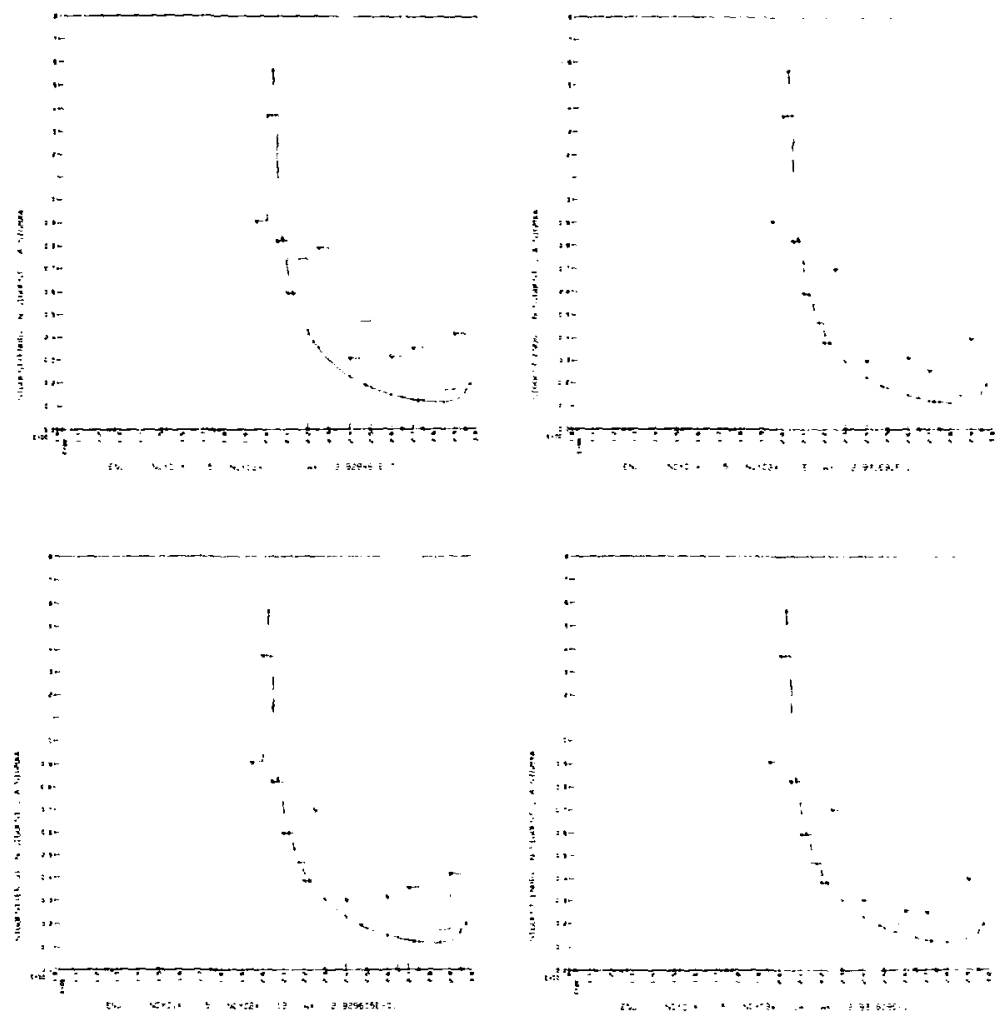

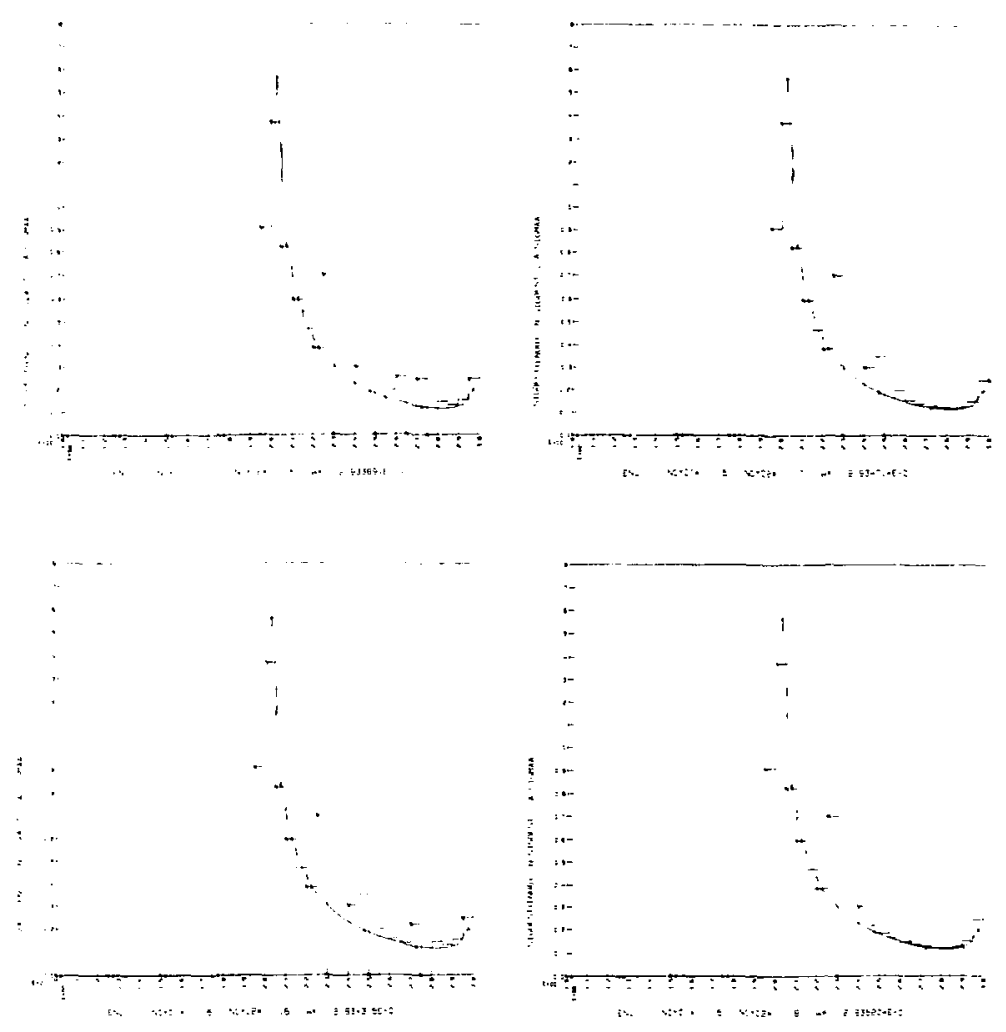

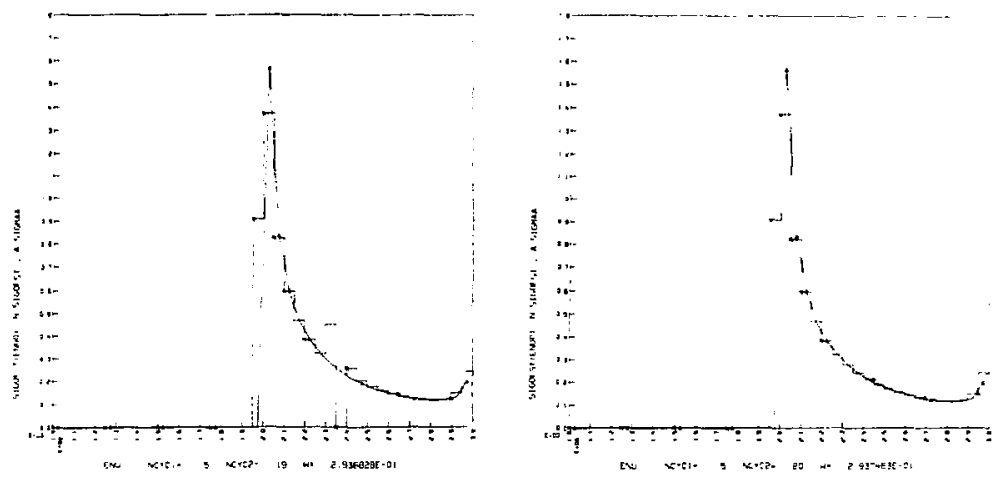